\title{
Effect of deposition time on surface plasmon resonance and Maxwell-Garnett absorption in RF-magnetron sputtered carbon-nickel films
}

\author{
VALi DALOUJi* \\ Department of Physics, Malayer University, Malayer, Iran
}

\begin{abstract}
In this work, carbon-nickel films were grown during four deposition times $(50 \mathrm{~s}, 90 \mathrm{~s}, 180 \mathrm{~s}$ and $600 \mathrm{~s})$ at room temperature on glass substrates by radio frequency magnetron sputtering. The optical absorption spectra of the films were investigated with a special emphasis on the surface plasmon resonance (SPR) of Ni nanoparticles. The optical absorption peaks caused by the surface plasmon resonance of Ni nanoparticles were observed in the wavelength range of $300 \mathrm{~nm}$ to $330 \mathrm{~nm}$. It has been shown that the surface plasmon resonance peaks exhibit a red shift and a blue shift depending on the deposition time. The red and blue shifts of the surface plasmon resonance in the absorption spectra of the films were observed with the increase and decrease of $\mathrm{Ni}$ nanoparticle size, respectively. The Ni nanoparticle size, dielectric function of carbon matrix $\varepsilon_{\mathrm{m}}$ and plasma frequency of free electrons $\omega_{\mathrm{p}}$ for the films deposited at deposition time of $180 \mathrm{~s}$ have maximum values of $80 \mathrm{~nm}, 0.401$ and $7.25 \times 10^{15} \mathrm{~s}^{-1}$, respectively. These observations are in a good agreement with the electrical resistivity measurements and Maxwell-Garnett (M-G) effective medium theory (EMT).
\end{abstract}

Keywords: surface plasmon resonance (SPR); carbon-nickel films; deposition time; deposition rate

(C) Wroclaw University of Technology.

\section{Introduction}

Thin carbon-nickel films have many interesting properties which can be used in optic, electronic and coating technology [1-5]. The nonlinear optical properties of metal nanocomposite films have been widely investigated due to strong surface plasmon resonance (SPR) of metal nanoparticles in various dielectric matrixes, such as $\mathrm{SiO}_{2}$ [6], $\mathrm{Al}_{2} \mathrm{O}_{3}$ [7], $\mathrm{TiO}_{2}$ [8], $\mathrm{NiO}$ [9] and $\mathrm{ZnO}$ [10]. The SPR frequency is a significant characteristic parameter of the nonlinear optical properties which depends on content, size, and shape of metal nanoparticles, as well as the dielectric properties of metal particles and the surrounding matrix material [11]. Because of their interesting properties, the amorphous carbon a-C:Me $(\mathrm{Me}=\mathrm{Au}$, $\mathrm{Ag}, \mathrm{Cu}, \mathrm{Mn} . .$.$) have many applications as coating$ materials in biomedicine, electronics, mechanics and optics [12, 13]. The amorphous carbon-nickel

\footnotetext{
*E-mail: dalouji@yahoo.com
}

films, a-C:Ni, is characterized by distinct physical properties in comparison to carbide forming elements $[14,15]$. In previous reports we studied the effects of deposition rate and annealing temperature on the morphology and the optical properties of carbon-nickel films [16-18]. In the present work we investigate the effect of deposition time on the surface plasmon resonance (SPR) peaks of carbonnickel films.

\section{Experimental}

The carbon-nickel films have been prepared by RF-magnetron sputtering onto glass substrates using a mosaic target consisting of pure graphite and strips of pure nickel attached to the graphite. Before loading into the deposition chamber, the substrates were ultrasonically cleaned in acetone bath for $20 \mathrm{~min}$ and then dried in a hot air flow. The films were grown at room temperature in a deposition chamber evacuated to a base pressure of $5 \times 10^{-3} \mathrm{~Pa}$ and then the constant Ar working 
pressure of $4 \mathrm{~Pa}$ was settled and maintained by a throttle valve. Deposition of the films was done in a constant RF power regime at $400 \mathrm{~W}$. The films were deposited at different deposition times: $50 \mathrm{~s}$, $90 \mathrm{~s}, 180 \mathrm{~s}$ and $600 \mathrm{~s}$. The thickness of the films was measured by Tencor Alpha Step 500 profiler. The field emission scanning electronic microscopy (FESEM) images were used for the morphological characterization. Energy dispersive X-ray studies (EDAX) were carried out with an AMETEK EDAX analyzer. The transmittance spectra were obtained by a double beam UV-Vis spectrometer in the range of $250 \mathrm{~nm}$ to $1000 \mathrm{~nm}$ (Jasco V-630). The direct current electrical conductivity was measured by cooling the samples in a continuous $\mathrm{He}$ flow in a cryogenic unit (optical low temperature model CCS 450 USA) of the thermostatic chamber in the temperature range of $15 \mathrm{~K}$ to $500 \mathrm{~K}$. ORTEC (456, USA, $0 \mathrm{kV}$ to $3 \mathrm{kV}$ ) high voltage power supply, Metrix VX102A (FRANCE) and Keithley 196 System DMM (USA) electrometers were used for voltage and current measurements, in temperature range of $15 \mathrm{~K}$ to $500 \mathrm{~K}$.

\section{Results and discussion}

Fig. 1 shows the FESEM images of $\mathrm{C}-\mathrm{Ni}$ films deposited at different deposition times $50 \mathrm{~s}$ to $600 \mathrm{~s}$. As shown in the FESEM images, the size of the nickel nanoparticles increases for the films deposited at the deposition times of $50 \mathrm{~s}, 90 \mathrm{~s}$ and $180 \mathrm{~s}$, and at $180 \mathrm{~s}$ it achieves a maximum value of about $80 \mathrm{~nm}$. The size of the nanoparticles decreases then to about $20 \mathrm{~nm}$ after $600 \mathrm{~s}$ deposition (Table 1). The images indicate that the $\mathrm{Ni}$ nanoparticles are approximately spherical and dispersed in the amorphous carbon. Fig. 1e and Fig. 1f show the size distributions of $\mathrm{Ni}$ nanoparticles of $\mathrm{C}-\mathrm{Ni}$ films deposited at $180 \mathrm{~s}$ and $600 \mathrm{~s}$.

Fig. 2a shows the EDAX spectrum for the films obtained in the deposition time of $600 \mathrm{~s}$. This spectrum was recorded in a line scan mode and one may observe the presence of peaks characteristic of $\mathrm{C}, \mathrm{Ni}$ and $\mathrm{Si}$. Fig. $2 \mathrm{~b}$ shows that the Ni content, computed from the EDAX analysis, increased from
42 at.\% to 85 at.\% with the increase of the deposition time from $50 \mathrm{~s}$ to $180 \mathrm{~s}$, and then decreased to 56 at.\% for the films deposited in $600 \mathrm{~s}$.

Fig. 3 shows the experimental absorption spectra of the $\mathrm{C}-\mathrm{Ni}$ films deposited at different deposition times from $50 \mathrm{~s}$ to $600 \mathrm{~s}$ as a function of incident light wavelength. All the films exhibit an absorption peak in the wavelength region of $300 \mathrm{~nm}$ to $330 \mathrm{~nm}$ due to the SPR of Ni particles [19]. The deposition rate causes the increase of Ni nanoparticles size and enhanced intensity of the absorption peaks. The increase of $\mathrm{Ni}$ content causes the increase of bulk-like behavior, which manifests itself in the red shift of the surface plasmon resonance from $298 \mathrm{~nm}$ to $316 \mathrm{~nm}$. With increasing the deposition time from $180 \mathrm{~s}$ to $600 \mathrm{~s}$, the bandwidth of the absorption peak is narrowed and weakened. The increase of the deposition time manifests itself in the blue shift from $316 \mathrm{~nm}$ to $308 \mathrm{~nm}$. These characteristics may be due to increasing significance of the quantum size effect [20].

The dielectric function $\varepsilon(\omega)$ of a bulk metal has to be modified, giving rise to a size dependent dielectric function $\varepsilon(\omega, \mathrm{R})$ :

$$
\varepsilon(\omega, R)=\varepsilon^{b u l k}(\omega)-\varepsilon_{D}^{b u l k}(\omega)+\varepsilon_{D}(\omega, R)
$$

where $\varepsilon^{\text {bulk }}(\omega)$ describes the dielectric function of a bulk metal calculated from $\mathrm{n}$ and $\mathrm{k}$, whose values are obtained experimentally. The second term in this equation denotes the Drude dielectric function of a free electron gas and the third term denotes the dielectric function of a nanoparticle with a radius $\mathrm{R}$ defined by equation:

$$
\varepsilon_{D}(\omega, R)=1-\omega_{p}^{2} /\left(\omega^{2}+i \Gamma(R) \omega\right)
$$

where $\omega_{\mathrm{p}}$ represents the plasma frequency of free electron. The damping constant $\Gamma$ is described for metal nanosphers with diameters smaller than the electron mean free path:

$$
\Gamma(R)=v_{f}(1 / L+A / R)
$$

where $v_{\mathrm{f}}$ is Fermi velocity, $\mathrm{L}$ is the mean free path, $\mathrm{R}$ is the nanoparticle radius, and $\mathrm{A}$ is a proportionality constant $(\mathrm{A}=1$ for isotropic electron scattering) [21]. In the quasi-static regime where 

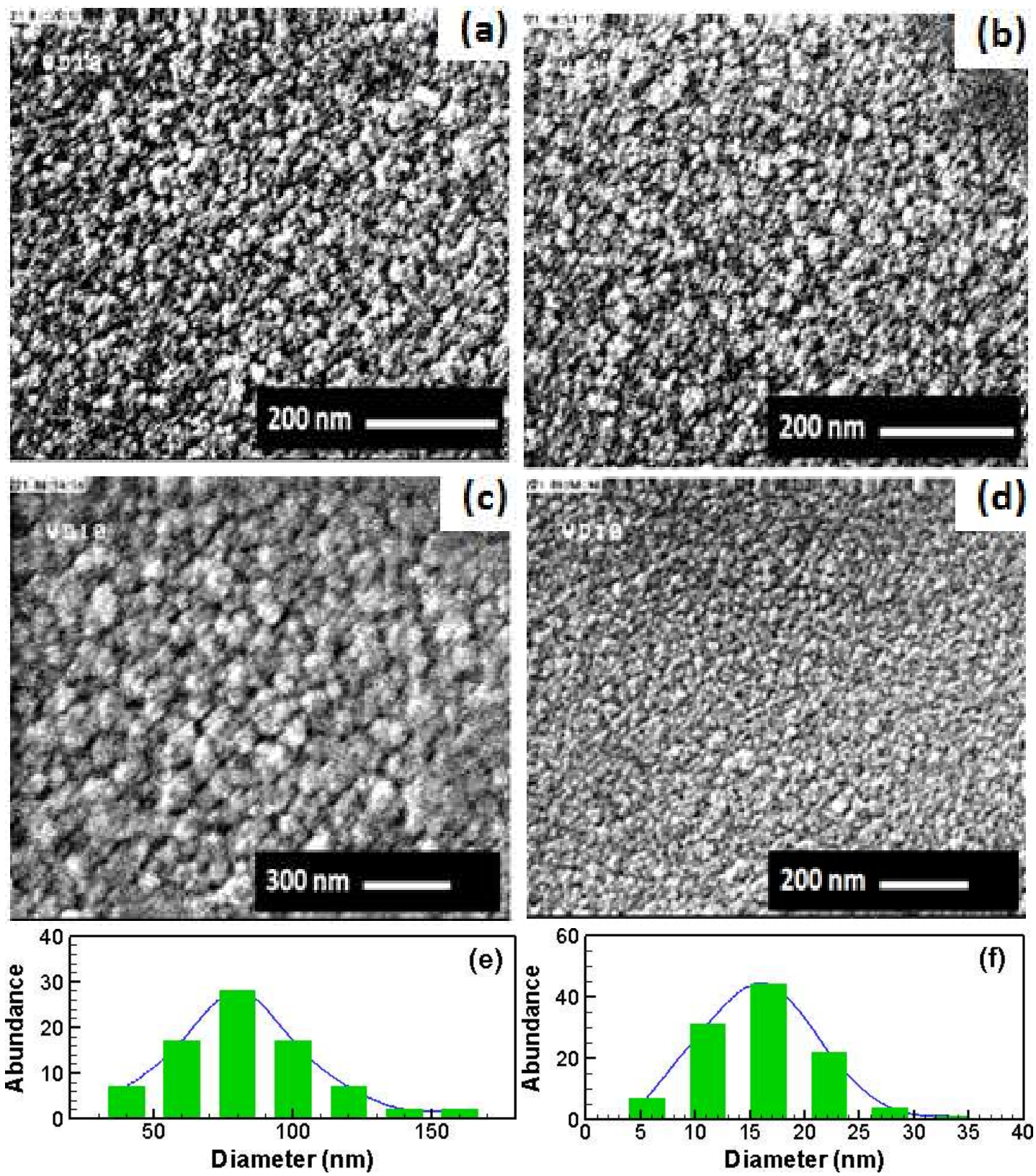

Fig. 1. FESEM images of C-Ni films deposited at deposition times of $50 \mathrm{~s}$ (a), $90 \mathrm{~s}$ (b), $180 \mathrm{~s}$ (c) and $600 \mathrm{~s}$ (d), and the size distribution of Ni nanoparticles of C-Ni films deposited at $180 \mathrm{~s} \mathrm{(e)} \mathrm{and} 600 \mathrm{~s}$ (f), respectively.

Table 1. Optical parameters of the C-Ni films deposited at different deposition times.

\begin{tabular}{ccccccc}
\hline $\begin{array}{c}\text { Deposition } \\
\text { time [s] }\end{array}$ & $\begin{array}{c}\mathrm{Ni} \\
\text { [at.\%] }\end{array}$ & $\begin{array}{c}\text { Ni nanoparticle } \\
\text { size [nm] }\end{array}$ & $\varepsilon_{\text {bulk }}$ & $\mathcal{E}_{\mathrm{m}}$ & $\begin{array}{c}\omega_{\rho} \times 10^{15} \\
{[1 / \mathrm{s}]}\end{array}$ & $\begin{array}{c}\gamma_{\mathrm{f}} \times 10^{17} \\
{[\mathrm{~cm} / \mathrm{s}]}\end{array}$ \\
\hline \hline 50 & 42 & 16.44 & 0.9991 & 0.05692 & 3.11 & 4.31 \\
90 & 48 & 16.76 & 1.1848 & 0.09144 & 4.21 & 4.26 \\
180 & 85 & 82.21 & 24.1889 & 0.40158 & 7.26 & 10.72 \\
600 & 56 & 17.95 & 11.0576 & 0.13541 & 5.37 & 7.32 \\
\hline
\end{tabular}



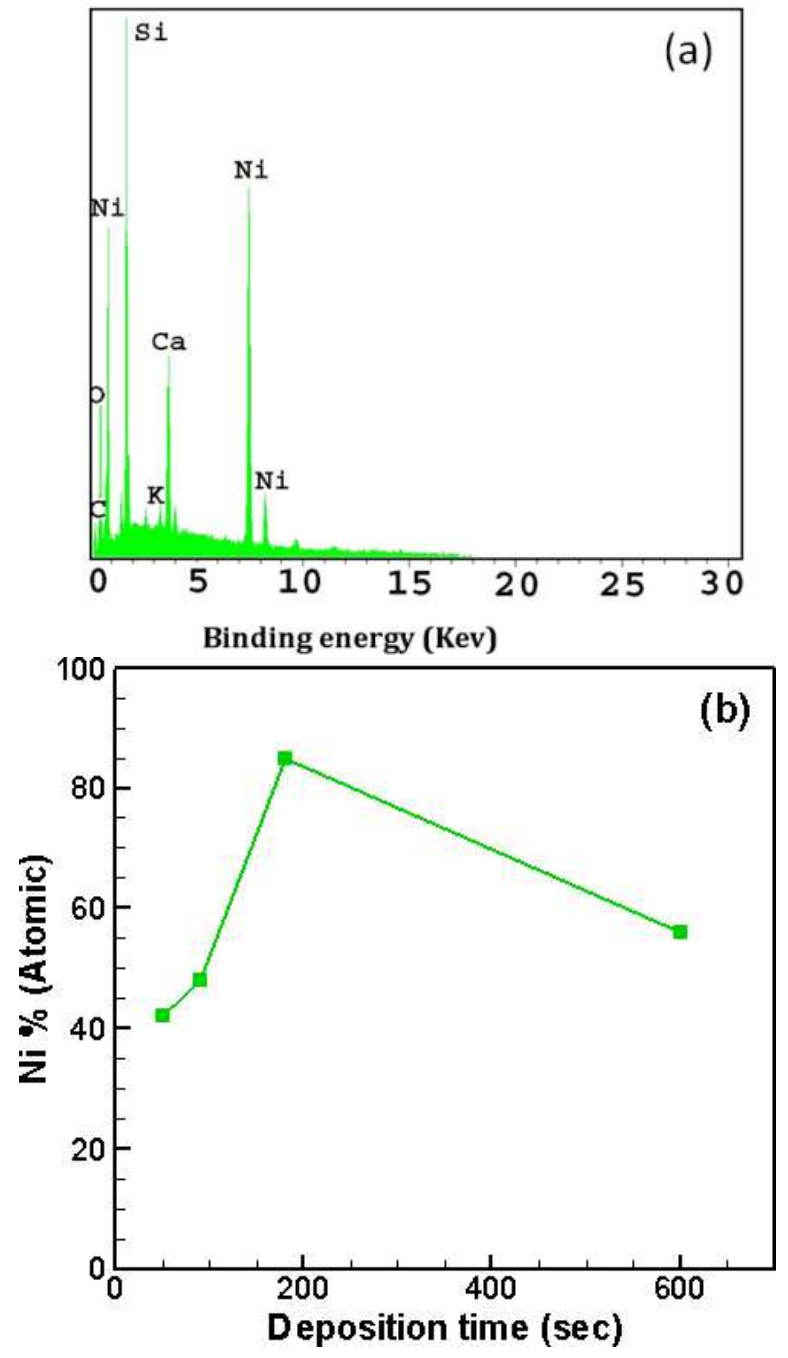

Fig. 2. EDAX spectrum of C-Ni film deposited at $600 \mathrm{~s}$ (a) and variation of $\mathrm{Ni}$ content with deposition time (b).

the radius $\mathrm{R}$ is significantly smaller than the incident wavelength $\lambda$, phase retardation and the mixing of higher-order multiple oscillations are negligible. In this case, a more simplified expression, based on the dipole approximation can be used, as given by [22]:

$$
\begin{aligned}
Q_{a b s}(\omega)= & 18 \pi V \varepsilon_{m}^{3 / 2} \varepsilon_{2}(\omega) / \lambda\left[\left(\varepsilon_{1}(\omega)+2 \varepsilon_{m}\right)^{2}\right. \\
& \left.+\varepsilon_{2}(\omega)^{2}\right]
\end{aligned}
$$

If $\varepsilon_{2}(\omega)$ is small or slightly dependent on $\omega$, the resonance condition in which the peak of the SPR band occurs is approximately fulfilled when $\varepsilon_{1}(\omega)=-2 \varepsilon_{\mathrm{m}}$, where $\mathrm{V}$ is the volume fraction of metal, $\varepsilon_{1}(\omega), \varepsilon_{2}(\omega)$ and $\varepsilon_{\mathrm{m}}$ are real and imaginary part of dielectric constant of the particles and dielectric constant of carbon matrix, respectively. The imaginary part of the particles dielectric constant is given as [22]:

$$
\varepsilon_{2}(\omega, R)=\varepsilon_{2}^{\text {bulk }}(\omega)+3 \omega_{p}^{2} v_{f} / 4 \omega^{3} R
$$

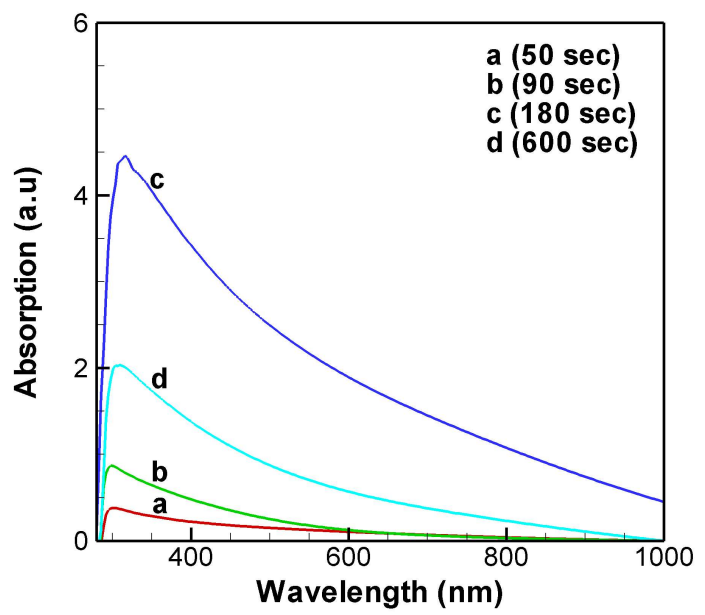

Fig. 3. The experimental absorption spectra of $\mathrm{C}-\mathrm{Ni}$ films for the films deposited at different deposition times.

The enhanced nonlinear optical absorption properties of the $\mathrm{C}-\mathrm{Ni}$ films deposited at the time up to $180 \mathrm{~s}$ could be attributed to the highly dispersed Ni nanoparticles whose size increases with its content. On the other hand, the weakening of the nonlinear optical absorption properties with further increase of the deposition time over $180 \mathrm{~s}$, results from the decrease in Ni content. The SPR peak shows a red shift trend with increasing deposition time from $50 \mathrm{~s}$ to $180 \mathrm{~s}$ and then turns to blue shift from $180 \mathrm{~s}$ to $600 \mathrm{~s}$. The red shift of the SPR peak in the films deposited in the time of $50 \mathrm{~s}$ to $180 \mathrm{~s}$ may be due to the quantum size effect. Besides the SPR shift there is the sharpening of the peak with increasing deposition time, which is attributed to the enhanced intrinsic free electron oscillation inside the metal particles. The broadening of the related SPR band may be due to the mean free path effect as well as the influence of conduction electron collisions with particle surfaces. 

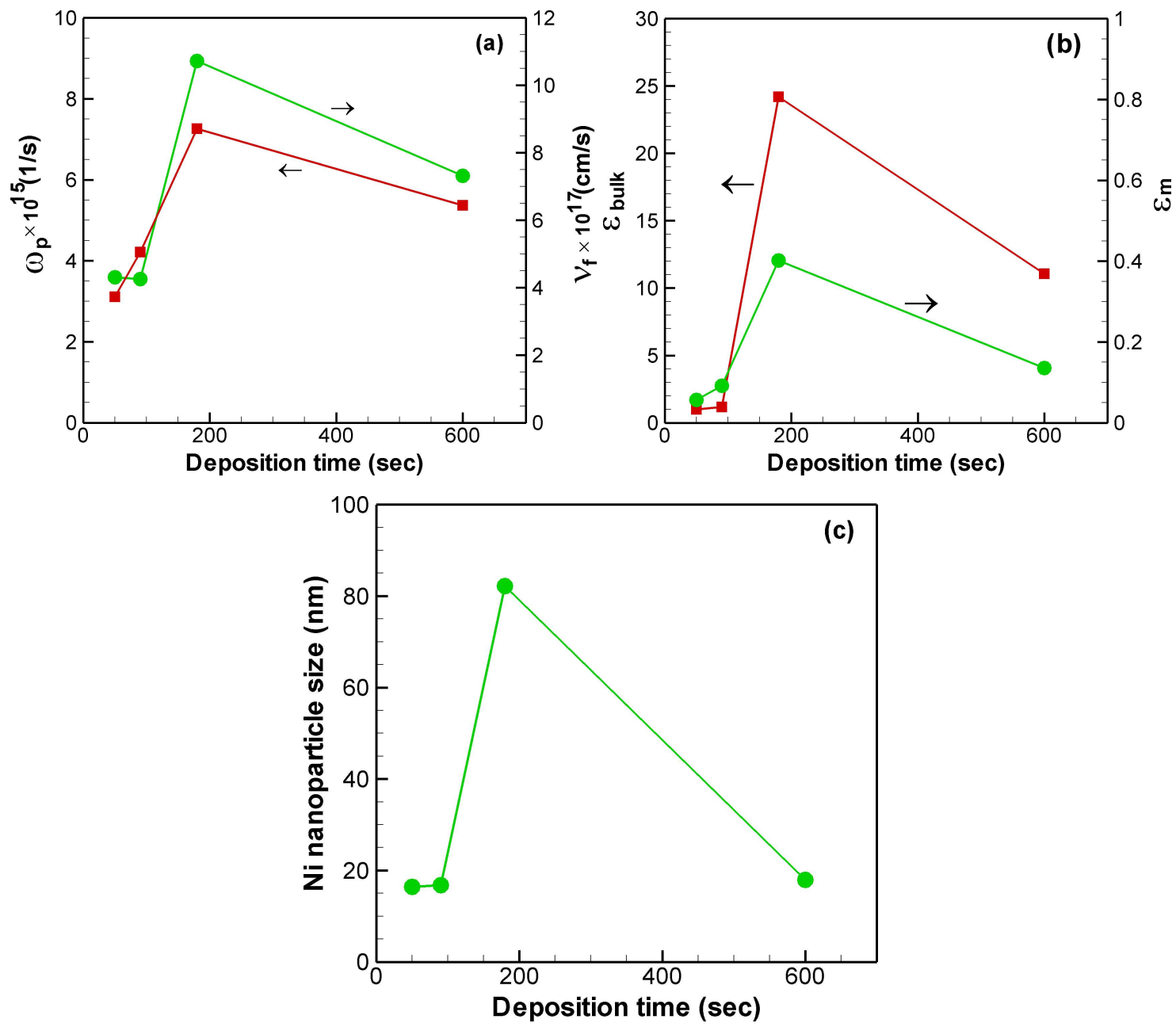

Fig. 4. Variation of $\omega_{\mathrm{p}}$ and $\gamma_{\mathrm{f}}(\mathrm{a}), \varepsilon^{\mathrm{bulk}}(\omega)$ and $\varepsilon_{\mathrm{m}}$, (b) and Ni nanoparticle size (c) of the C-Ni films with respect to the deposition time.

The blue shift accompanying the narrowing of the peak in the films deposited from $180 \mathrm{~s}$ to $600 \mathrm{~s}$ is related to decreasing in $\mathrm{Ni}$ content and Ni nanoparticle size. Therefore, the optical properties of the $\mathrm{C}-\mathrm{Ni}$ films including the position and intensity of the absorption peak can be controlled by altering $\mathrm{Ni}$ content according to the requirement of a practical application. Fig. 4a shows the variation of $\omega_{\mathrm{p}}$ and $v_{\mathrm{f}}$ with respect to deposition time. It can be seen that due to the increase of free carrier concentration in the samples deposited up to $180 \mathrm{~s}, \omega_{\mathrm{p}}$ and $v_{f}$ increase and then, due to decreasing free carrier concentration in the samples deposited from $180 \mathrm{~s}$ to $600 \mathrm{~s}$, they decrease. Fig. 4b shows the variation of $\varepsilon^{\text {bulk }}(\omega)$ and $\varepsilon_{\mathrm{m}}$ with respect to the deposition time. It can also be seen that due to increasing free carrier concentration in the samples obtained in the deposition times up to $180 \mathrm{~s}$, $\varepsilon^{\text {bulk }}(\omega)$ and $\varepsilon_{\mathrm{m}}$ increase and then decrease. Fig. 4c shows the variation of the Ni nanoparticle size with respect to deposition time. As shown in FESEM images, due to increasing deposition rate up to $180 \mathrm{~s}$, the Ni nanoparticle size increases and then over $180 \mathrm{~s}$, it decreases due to decreasing deposition rate. At the low deposition rate and high deposition time, there are some adsorbed atoms which have enough time to migrate to the sites where the surface energy is low enough to be covered by the coming atom and, as a result, the film surface is very smooth and has small particle size. 
Therefore, the increase of deposition time causes changing of deposition mode, deposition rate and hence, strongly affects the size of the particles.

Fig. 5 shows the theoretical Maxwell-Garnett absorption spectra of $\mathrm{C}-\mathrm{Ni}$ films with respect to wavelength. The plasmon resonant modes are described by Maxwell-Garnett model by introducing a shape-dependent factor $\mathrm{K}=1 /(\mathrm{q}-1)$ where $\mathrm{q}$ is the depolarization factor. The Maxwell-Garnett absorption theory can be written in terms of the particle polarizability $\alpha$ as:

$$
Q_{a b s}=k \operatorname{Im}(\alpha)
$$

and

$$
\alpha=(V / 3 q)\left(\varepsilon_{m}-\varepsilon_{p}\right) /\left(\varepsilon_{m}+\kappa \varepsilon_{p}\right)
$$

where $\mathrm{k}$ is the wave vector and $\mathrm{V}$ is the particle volume.

The optical absorption behavior of the films can be stated by Maxwell-Garnett (M-G) effective medium theory (EMT) and defined by [20]:

$$
\begin{aligned}
\varepsilon_{e f f}= & \varepsilon_{m}\left[\left(\varepsilon_{p}+2 \varepsilon_{m}+2 V\left(\varepsilon_{p}-\varepsilon_{m}\right)\right) /\left(\varepsilon_{p}+2 \varepsilon_{m}\right.\right. \\
& \left.\left.-2 V\left(\varepsilon_{p}-\varepsilon_{m}\right)\right)\right]
\end{aligned}
$$

where $\varepsilon_{\mathrm{p}}, \varepsilon_{\mathrm{m}}, \varepsilon_{\text {eff }}$ and $\mathrm{V}$ are the dielectric function of the particles, the dielectric function of the matrix, the effective dielectric function of the films and the volume fraction occupied by the spherical particles, respectively [23].

The absorption maximum occurs at a wavelength satisfying:

$$
\varepsilon_{p}+2 \varepsilon_{m}-2 V\left(\varepsilon_{p}-\varepsilon_{m}\right)=0
$$

It can be seen that with an increase of deposition time up to $180 \mathrm{~s}$ Maxwell-Garnett absorption spectra and the imaginary part of the effective dielectric constant $\varepsilon_{\text {eff }}$ increase and then over $180 \mathrm{~s}$ they decrease. The increase in absorption spectra in the films deposited from $50 \mathrm{~s}$ to $180 \mathrm{~s}$ is due to the increase in the concentration of $\mathrm{Ni}$ atoms, whereas the decrease in the absorption spectra in the films deposited from $180 \mathrm{~s}$ to $600 \mathrm{~s}$ is due to the decrease in concentration of $\mathrm{Ni}$ atoms.
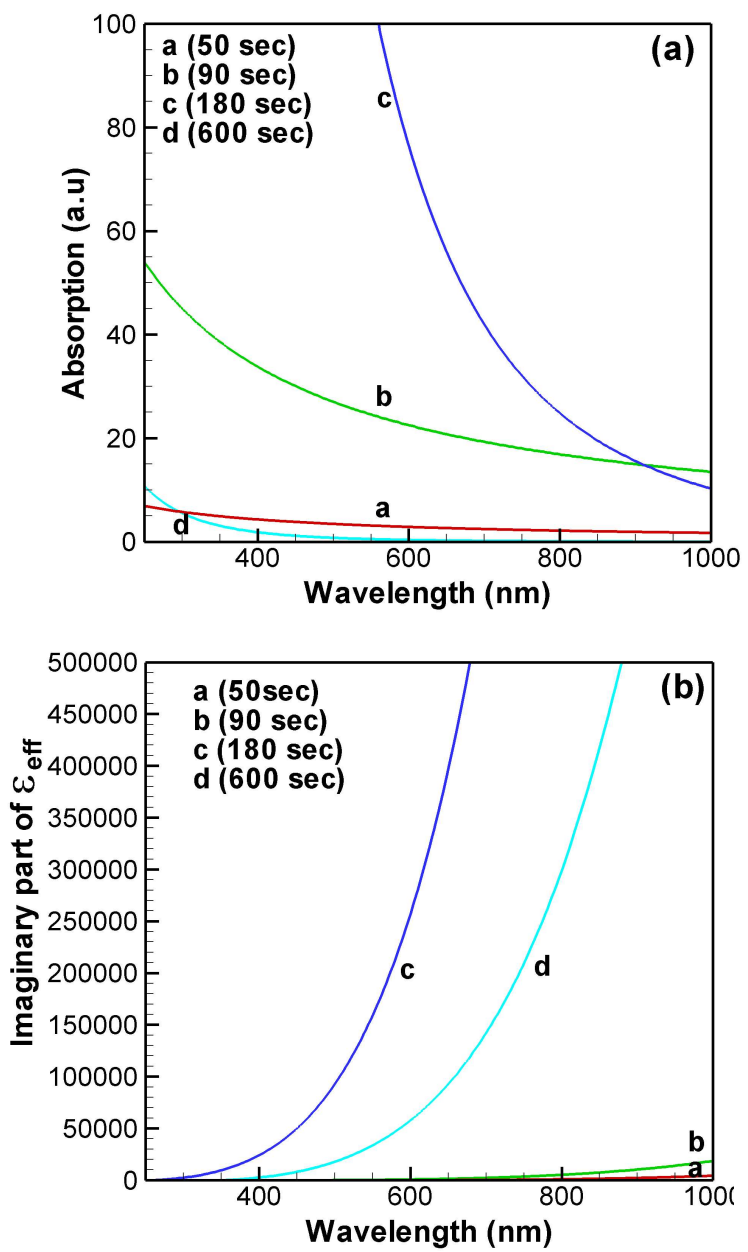

Fig. 5. The theoretical Maxwel-Garnett absorption spectra (a) and the imaginary part of the effective dielectric constant $\varepsilon_{\text {eff }}$ (b) of C-Ni films for the films obtained at different deposition times.

Fig. 6 shows the variation of resistivity with temperature for the films deposited at different deposition times of $50 \mathrm{~s}$ to $600 \mathrm{~s}$. The resistivity of the films decreases with increasing temperature showing the semiconducting behavior. It is evident that in the entire temperature range $15 \mathrm{~K}$ to $500 \mathrm{~K}$, the resistivity decreases with increasing deposition time from $50 \mathrm{~s}$ to $180 \mathrm{~s}$ and then it increases for the deposition times from $180 \mathrm{~s}$ to $600 \mathrm{~s}$. The decrease of resistivity could be due to the increase of nanoparticle size which leads to the decrease in grain boundary scattering. On the other hand, the increase of resistivity at the deposition time above 
180 s may be due to the increase of grain boundary scattering.

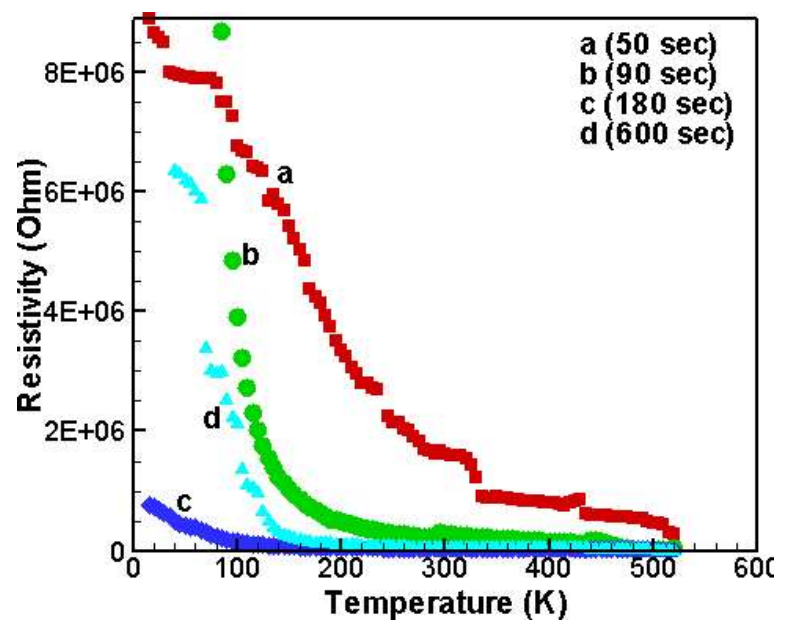

Fig. 6. Variation of resistivity with temperature for the films deposited for $50 \mathrm{~s}, 90 \mathrm{~s}, 180 \mathrm{~s}$ and $600 \mathrm{~s}$.

\section{Conclusions}

In this study, we showed that deposition time and deposition rate play an important role in the optical properties of $\mathrm{C}-\mathrm{Ni}$ films. It is observed that the films deposited in $180 \mathrm{~s}$ have maximum surface plasmon resonance peak intensity and nickel concentration. It can be seen that at $180 \mathrm{~s} \omega_{\mathrm{p}}$, $v_{\mathrm{f}}, \varepsilon^{\text {bulk }}(\omega)$, the size of Ni nanoparticles and the dielectric function matrix $\varepsilon_{\mathrm{m}}$ of the $\mathrm{C}-\mathrm{Ni}$ films achieve maximum values and over $180 \mathrm{~s}$ they decrease.

\section{References}

[1] Talu S., Bramowicz M., Kulesza S., Shafikhani A., Ghaderi A., MaShaYeKhi F., Solaymani S., Ind. Eng. Chem. Res., 54 (2015), 8212.

[2] Stach S., GarczyK Z., Talu S., Solaymani S., Ghaderi A., Moradian R., Nezafat Negin B., Elahi S.M., Gholamali H., J. Phys. Chem. C, 119 (2015), 17887.

[3] Talu S., Stach S., Ghodselahi T., Ghaderi A., Solaymani S., Boochani A., Garczyk Z., J. Phys. Chem. B, 119 (2015), 5662.
[4] Talu S., Stach S., Solaymani S., Moradian R., Ghaderi A., Hantehzadeh M.R., Elahi S.M., GARCZYK Z., IZADYAR S., J. Electroanal. Chem., 749 (2015), 31.

[5] Ghodselahi T., Vaseghi M.A., Shafiekhani A., J. Phys. D Appl. Phys., 42 (2009), 015308.

[6] Sangapour P., Akhavan O., Moshfegh A.Z., $J$. Alloy. Comp., 486 (2009) 22.

[7] Celep G., Cottaancin E., Lerme J., Pellarine M., Arnaud L., Huntzinger J.R., Vialle J.L., Broyer M., Palpant B., Boisron O., Melinon P., Phys. Rev. B, 70 (2004) 165409.

[8] LiaO H.B., XiaO R.F., Wong H., Wong K.S., Wong G.K.L., Appl. Phys. Lett., 72 (1998) 1817.

[9] Ferreira F.F., Haddad P.S., Fantini M.C.A., BRITO G.F.S., Solid Stat Ionics, 165 (2003), 0161.

[10] Liao H.B., Wen W.J., Wong G.K.L., Yong G.Z., Opt. Lett., 28 (2003), 1790.

[11] Kreibig U., Vollmer M., Optical Properties of Metal Clusters, Springer-Verlag, Berlin - Heidelberg New York, 1995.

[12] EndRino J.L., ESCOBAR GALINDO R., ZHANG H.S., Allen M., Gago R., Espinosa A., Anders A., Surf. Coat. Tech., 202 (2008), 3675.

[13] Ghodselahi T., Vaseghi M.A., Shafikhani A., Ahmadi M., Panahandeh M., Heidari SaAni M., Physica B, 405 (2010), 3949.

[14] Korotcenkov G., Han S.D., Stetter J.R., Chem. Rev., 109 (2009), 1402.

[15] Kambhampati D.K., Knoll W., Curr. Opin. Colloid Interf. Sci., 4 (1999), 273.

[16] Elahi S.M., Dalouji V., Valedbagi S., Adv. Mater. Sci. Eng., 2013 (2013), 506549.

[17] Elahi S.M., Dalouji V., Mehrparvar D., ValedBAGI S., Mol. Cryst. Liq. Cryst., 587 (2013), 105.

[18] Dalouji V., Elahi S.M., J. Korean Phys. Soc., 64 (2014), 857.

[19] Fox M., Optical Properties of Solids, Oxford University Press Inc., New York, 2001.

[20] Wang S.-J., Zhang B.-P., Yan L.-P., Deng W., J. Alloy. Comp., 509 (2011), 5731.

[21] Hashimoto S., Werner D., Uwada T., J. Photoch. Photobio. C, 13 (2012), 28.

[22] Naderi S., Ghaderi A., Solaymani S., Golzan M.M., Eur. Phys. J. Appl. Phys., 58 (2012), 20401.

[23] Dalacu D., Martinu L., J. Appl. Phys., 87 (2000), 228.
Received 2015-07-25 Accepted 2016-03-11 